\title{
Villous adenomas and carcinoma of the duodenum in Gardner's syndrome
}

\author{
J. Sinha and R.C.N. Williamson
}

Department of Surgery, Royal Postgraduate Medical School, Hammersmith Hospital, Du Cane Road, London W12 OHS, UK.

\begin{abstract}
Summary: Patients with Gardner's syndrome are increasingly found to have polyps on routine upper gastrointestinal endoscopy, and their risk of developing periampullary carcinoma is between $3-$ $12 \%$. We report a 45 year old man with Gardner's syndrome who presented with periampullary carcinoma 5 years after colectomy. Review of the literature amassed another 21 cases of periampullary carcinoma in patients with Gardner's syndrome.
\end{abstract}

\section{Introduction}

Familial adenomatous polyposis (FAP, also known as familial polyposis coli) and related syndromes, such as Gardner's syndrome, are genetically determined growth disorders that predispose to tumours in various parts of the body. ${ }^{1}$ The mode of inheritance is autosomal dominant, and the FAP gene has been localized to chromosome $5 .^{2}$ The association of polyposis coli, soft tissue tumours and osteomas was originally described by Gardner in $1951 .{ }^{3}$ With the increasing availability of fibreoptic endoscopy, gastric and duodenal polyps have been found in $46 \%$ of patients with FAP and Gardner's syndrome, ${ }^{4}$ although polyps in up to $100 \%$ of Japanese patients have been reported. ${ }^{5}$ Periampullary carcinoma was described as a complication of Gardner's syndrome in $1967 .^{6}$ Since that time we have found 21 examples of this association in the world literature, to which we now add a further case.

\section{Case report}

A 45 year old man presented in 1987 with a short history of painless obstructive jaundice. Six years earlier Gardner's syndrome had been diagnosed on the basis of an osteoma at each angle of the mandible (Figure 1), soft tissue tumours in the scalp and on the dorsum of both feet and multiple colonic polyps. He had undergone abdominal colectomy with ileorectal anastomosis in 1982 and was followed up with annual proctoscopy and rectal

Correspondence: Professor R.C.N. Williamson, M.A., M.D., M.Chir., F.R.C.S.

Accepted: 7 June 1988 fulguration. Multiple small gastric and duodenal polyps were diagnosed endoscopically in 1985. There was no previous family history, but his 17 year old son also has Gardner's syndrome.

Ultrasound examination showed a dilated common bile duct and gallbladder with a small mass in the region of the ampulla. At endoscopy there were multiple tiny polyps carpeting the stomach and numerous polyps throughout the duodenum. A larger ulcerated tumour was observed at the papilla; biopsies showed villous adenoma. ERCP (Figure 2) showed gross dilatation of the biliary and pancreatic ducts. Hypotonic duodenography confirmed a $4 \mathrm{~cm}$ periampullary mass, and at least two more sizeable polyps were seen in the proximal jejunum.

The patient was submitted to conservative proximal pancreatectomy, ${ }^{7}$ preserving the stomach, pylorus and first $5 \mathrm{~cm}$ of the duodenum. Besides the obstructing tumour in the descending duodenum, a second soft polypoid lesion was palpable just distal to the duodenojejunal flexure and was included in the resection specimen. Recovery was uneventful and the patient was discharged at 12 days. Polyps were seen throughout the excised segment of small intestine, and all those sampled proved to be villous adenomas. The larger lesion at the papilla showed early invasive adenocarcinoma.

\section{Discussion}

The genetic and premalignant nature of familial adenomatous polyposis has been recognized since Cripps $^{8}$ described two members of the same family

(C) The Fellowship of Postgraduate Medicine, 1988 


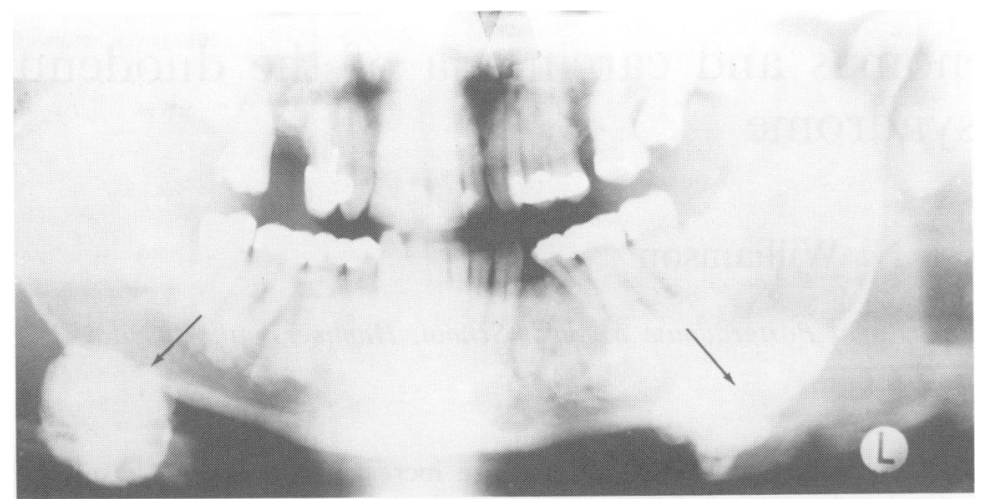

Figure 1 Radiograph of the mandible showing an osteoma at each angle (arrowed).

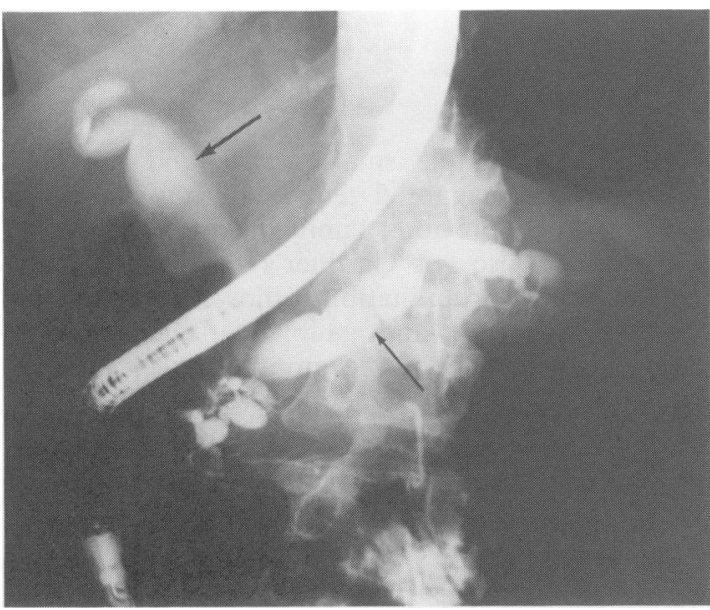

Figure 2 Endoscopic retrograde cholangiopancreatogram showing dilatation of the bile duct (broad arrow) and pancreatic duct (narrow arrow) behind a duodenal tumour obstructing the papilla.

with rectal polyps in 1882 and Handford ${ }^{9}$ noted an association with carcinoma of the colon in 1890 . It is increasingly apparent that the polyposis syndromes can affect not just the large bowel but the entire gastrointestinal tract, and extraintestinal manifestations are frequently present as well. The incidence of periampullary tumours in Gardner's syndrome has been estimated at between 3$12 \% .^{10,11}$ Patients with Gardner's syndrome may have a 100-to 200-fold increased risk of developing periampullary carcinoma compared with the general population. ${ }^{10}$

The clinical features of the 22 patients unearthed by our review of the literature are shown in Table I. Interestingly, there is a male predominance $(70 \%)$, even though the mode of inheritance of
Gardner's syndrome is autosomal dominant and $\mathrm{J}$ not sex-linked, but the number of patients is small. o The interval between diagnosis of colorectal polyps $\&$ and periampullary carcinoma ranges between 0-30 은 years (median 15 years; mean 14.2 years). In 16 of 20 cases other duodenal polyps were stated to be $z$ present. Only 9 of these 16 case reports described the type of polyp, viz. 8 adenomas and 1 hamartoma. The type of adenoma was classified in 4 of the 8 cases, and all 4 were villous (papillarg adenomas. Adenocarcinomas are known to develog more frequently in villous adenomas than in other. adenomas of the small intestine. ${ }^{12}$ Adenocarcino ${ }^{+}$ mas of the small bowel are rare, being 100-160 times less prevalent than carcinomas of the stomach or large intestine, but when they do occur they have a marked proximal distribution: over $40 \% \stackrel{\mathbb{Q}}{\Omega}$ arise within the duodenum, and no less than $80-\overrightarrow{\vec{B}}$ $90 \%$ within the duodenum and proximal jeju- $\frac{0}{3}$ num. ${ }^{12,13}$ Gastric polyps found in patients with FAP and Gardner's syndrome are of the fundic gland type, and gastric adenomas are extremely uncommon. ${ }^{4}$

Surgical management of periampullary carcinoma in Gardner's syndrome presents a dilemma because 3 of the extent of gut actually or potentially affected. 8 Our patient had already undergone colectomy and $₹$ had additional polyps in the stomach and jejunum, 은 for which radical resection seemed impractical. Hence a conservative pancreatectomy was performed, preserving the pylorus and proximal duodenum (which was clear of polyps) together with $N$ the jejuno-ileum, but fortunately removing a large $N$ polyp in the region of the duodeno-jejunal flexure. N The advantages of conservative pancreatectomy $\omega$ over the traditional Whipple's operation are avoidance of the post-gastrectomy syndromes and marginal ulceration, return of normal gastric function and improved postoperative weight gain. ${ }^{7}$ 
Table I Periampullary carcinoma in patients with Gardner's syndrome

\begin{tabular}{|c|c|c|c|c|c|c|c|}
\hline \multirow[b]{2}{*}{ Casc } & \multirow[b]{2}{*}{ (riference) } & \multirow[b]{2}{*}{ Sex } & \multicolumn{2}{|c|}{ Age at diagnosis } & \multicolumn{3}{|c|}{$\begin{array}{l}\text { Associated stigmata of } \\
\text { Gardner's syndrome }\end{array}$} \\
\hline & & & $\begin{array}{l}\text { of colonic } \\
\text { polyps }\end{array}$ & $\begin{array}{c}\text { of periampullary } \\
\text { tumour }\end{array}$ & Osteomas & $\begin{array}{l}\text { Soft tissue } \\
\text { tumour }\end{array}$ & $\begin{array}{c}\text { Supernumerary } \\
\text { teeth }\end{array}$ \\
\hline 1 & (16) & M & 36 (PM) & 36 (PM) & + & + & - \\
\hline 2 & (6) & M & 24 & 44 & + & + & + \\
\hline 3 & (6) & $\mathrm{F}$ & 37 & 38 (PM) & + & - & - \\
\hline 4 & (17) & $\mathrm{F}$ & 35 & 36 & + & + & - \\
\hline 5 & (18) & M & 33 & 40 & + & + & + \\
\hline 6 & (19) & M & 29 & 49 & + & + & - \\
\hline 7 & (19) & $\mathrm{U}$ & $\mathrm{U}$ & $\mathrm{U}$ & $\mathrm{U}$ & $\mathrm{U}$ & $\mathrm{U}$ \\
\hline 8 & (19) & $\mathrm{U}$ & $\mathrm{U}$ & $\mathrm{U}$ & $\mathrm{U}$ & $\mathrm{U}$ & $\mathrm{U}$ \\
\hline 9 & (20) & $\mathbf{M}$ & 31 & 45 & + & + & - \\
\hline 10 & (21) & $\mathbf{M}$ & 23 & 40 & + & + & + \\
\hline 11 & (22) & M & 37 & 63 & + & + & - \\
\hline 12 & (22) & $\mathrm{F}$ & 26 & 39 & - & + & - \\
\hline 13 & (23) & $\mathbf{M}$ & 47 & 49 & - & + & + \\
\hline 14 & (24) & M & 44 & 60 & + & - & - \\
\hline 15 & (25) & M & 22 & 50 & - & + & - \\
\hline 16 & (10) & M & 35 & 59 & + & + & + \\
\hline 17 & (10) & $\mathbf{M}$ & 68 & 68 & - & - & - \\
\hline 18 & (15) & M & 29 & 48 & + & + & - \\
\hline 19 & (26) & $\mathrm{F}$ & 25 & 55 & - & + & - \\
\hline 20 & (27) & $\mathrm{F}$ & 29 & 56 & - & + & - \\
\hline 21 & (28) & $\mathrm{F}$ & 29 & 41 & - & - & + \\
\hline 22 & (this report) & M & 39 & 45 & + & + & + \\
\hline
\end{tabular}

Periampullary carcinoma is the second commonest neoplasm and cause of death in patients with FAP. ${ }^{14.15}$ Indeed, in one series of patients with FAP undergoing colectomy and ileorectal anastomosis at the Cleveland Clinic over the last 25 years, more patients have died of periampullary carcinoma than of rectal carcinoma. ${ }^{1}$ The need for routine upper gastrointestinal endoscopy in patients with FAP and Gardner's syndrome is clearly appar- ent, ${ }^{4,10,15}$ with a high index of suspicion for those polyps found to be villous adenomas.

\section{Acknowledgements}

We thank Dr J.M.T. Willoughby, D.M., F.R.C.P., Consultant Physician at Lister Hospital, Stevenage, who diagnosed and referred this patient.

\section{References}

1. Jagelman, D.G. Extracolonic manifestations of familial polyposis coli. Cancer Genet Cytogenet 1987, 27: 319-325.

2. Bodmer, W.F., Bailey, C.J., Bodmer, J. et al. Localisation of the gene for familial adenomatous polyposis on chromosome 5. Nature 1987, 328: 614-616.

3. Gardner, E.J. A genetic and clinical study of intestinal polyposis, a predisposing factor for carcinoma of the colon and rectum. Am J Hum Genet 1951, 3: 167-176.

4. Sarre, R.G., Frost, A.G., Jagelman, D.G., Petras, R.E., Sivak, M.V. \& McGannon, E. Gastric and duodenal polyps in familial adenomatous polyposis: a prospective study of the nature and prevalence of upper gastrointestinal polyps. Gut 1987, 28: 306-314.

5. Yao, T., Iida, M., Ohsato, K., Watnabe, H. \& Omae, T. Duodenal lesions in familial polyposis of the colon. Gastroenterology 1977, 73: 1086-1092.

6. MacDonald, J.M., Davis, W.C., Crago, H.R. \& Berk, M.D. Gardner's syndrome and periampullary malignancy. Am J Surg 1967 113: 425-430.

7. Cooper, M.J. \& Williamson, R.C.N. Conservative pancreatectomy. Br J Surg 1985, 72: 801-803.

8. Cripps, W.H. Two cases of disseminated polyposis of the rectum. Trans Pathol Soc Lond 1882, 33: 165-168.

9. Handford, H. Disseminated polyps of the large intestine becoming malignant. Trans Pathol Soc Lond 1890, 41: 133 . 
10. Pauli, R.M., Pauli, M.E. \& Hall, J.G. Gardner's syndrome and periampullary malignancy. Am J Med Genet 1980, 6: 205-219.

11. Bussey, H.J.R. Familial Polyposis Coli. The Johns Hopkins University Press, Baltimore, 1975.

12. Perzin, K.H. \& Bridge, M.F. Adenomas of the small intestine: a clinicopathologic review of 51 cases and study of their relationship to carcinoma. Cancer 1981, 11: 323-329.

13. Williamson, R.C.N., Welch, C.E. \& Malt, R.A. Adenocarcinoma and lymphoma of the small intestine. Distribution and etiological associations. Ann Surg 1983, 197: 172-178.

14. Jones, T.R. \& Nance, F.C. Periampullary malignancy in Gardner's syndrome. Ann Surg 1975, 185: 565-573.

15. Sugihara, K. Muto, T., Kamiya, J., Konishi, F., Sawada, T. \& Morioka, Y. Gardner's syndrome associated with periampullary carcinoma, duodenal and gastric adenomatosis. Report of a case. Dis Col Rectum 1982, 25: 766-771.

16. Cabot, R.C. Case records of the Massachusetts General Hospital, Case No. 21061. N Engl J Med 1935, 212: 263-267.

17. McFarland, P.H., Scheetz, W.L. \& Knisley, R.E. Gardner's syndrome: report of two families. J Oral Surg 1968, 26: 632-638.

18. Duncan, B.R., Dohner, V.A. \& Priest, J.H. The Gardner syndrome: need for early diagnosis. $J$ Pediatr 1968, 72: 497-505.

19. Parks, T.G., Bussey, H.J.R. \& Lockhart-Mummery, H.E. Familial polyposis coli associated with extracolonic abnormalities. Gut 1970, 11: 323-329.

20. Coli, R.D., Moore, J.P., Lamarche, P.H., Dellica, F.G. \& Thayer, W.R. Gardner's syndrome. A revisit to a previously described family. Am J Dig Dis 1970 , 15: $551-568$.
21. Stalport, J. \& Letawe, P. Syndrome de Gardner associe a une degenerescence maligne d'un polype du sphincter d'Oddi. Acta Gastro-Enterol Belg 1971, 34: 644-651.

22. Schnur, P.L., David, E., Brown, P.W., Beahrs, O.H., जे Remine, W.H. \& Harrison, E.G. Adenocarcinoma of $\bar{C}$ the duodenum and the Gardner syndrome. JAMA 1973, 223: 1229-1232.

23. Suzanne, J., Camelot, G., Miguet, J.P. et al. Syndrome de Gardner et adenocarcinome duodenal. Q Etude d'un cas et revue de la litterature. Gastroenterol ڤొ Clin Biol 1977, 1: 455-460.

24. Melmed, R.N. \& Bouchier, I.A.D. Duodenal involve- $\vec{\circ}$ ment in Gardner's syndrome. Gut 1972, 13: 524-527.

25. Mir-Madjlessi, S.H., Farmer, R.G., Hawk, W.A. \& Turnbull, R.B. Adenocarcinoma of the ampulla of $\frac{D}{0}$ Vater associated with familial polyposis coli. Report of a case. Dis Colon Rectum 1973, 16: 542-546.

26. Scully, R.E., Mark, E.J. \& McNeely, B.U. Case records of the Massachusetts General Hospital. Case No. 50-182. N Engl J Med 1982, 307: 1566-1573.

27. Komorowski, R.A., Tresp, M.G. \& Wilson, S.D. $\infty$ Pancreaticobiliary involvement in familial polyposis $\mathscr{Q}$ coli/Gardner's syndrome. Dis Colon Rectum 1986, 29: 윽 55-58.

28. Berk, T., Friedman, L.S., Goldstein, S.D., Marks, G.P. \& Rosato, F.E. Relapsing acute pancreatitis as the presenting manifestation of an ampullary neoplasm in a patient with familial polyposis coli. $A m J$ Gastroenterol 1985, 80: 627-629. 